\title{
Playing the Language Game of Family Mediation: Implications for Mediator Ethics
}

\author{
Rachael Field and Jonathan Crowe*
}

\begin{abstract}
Over the last 20 to 30 years, the use of mediation in Australia to resolve family disputes has grown significantly. Since the 2006 reforms to the Family Law Act 1975 (Cth), family dispute resolution, a common form of which is family mediation, has effectively become a compulsory first step in post-separation parenting disputes that enter the family law system. There are many good reasons for encouraging parties to participate in family mediation. Mediation is a flexible, cost-effective, time-efficient, more humane, less adversarial way for families to manage and resolve post-separation disputes. Family mediation is also a process that enables party self-determination, empowering the parties to determine together the best arrangements for their family into the future. However, vigilance is required if the capacity of each party to negotiate towards a mutually agreeable outcome is to be effectively sustained and the full potential of the benefits of mediation are truly to be achieved. In this article, we use Ludwig Wittgenstein's concept of a language game and the related notion of a clash of genres to explore some of the underlying conventions and expectations that create challenges for the parties in family mediation. We then consider how mediators might respond to these challenges and the implications this holds for mediator ethics.
\end{abstract}

\section{INTRODUCTION}

Family mediation is now the predominant system used in Australia for the resolution of post-separation family disputes. ${ }^{1}$ The process has many benefits, including its informality, flexibility and less confrontational nature; its ability to promote party self-determination; and its focus on the parties' mutual needs and interests, along with the best interests of the children. ${ }^{2}$ Family mediation is intentionally designed to be a supportive

* The authors would like to thank Olivia Rundle, Camilla Baasch Andersen and the anonymous referees for their valuable comments. An earlier version of this article was presented at the Australian Dispute Resolution Research Network Roundtable at the University of New South Wales in September 2015. Thanks to all who took part in the discussion.

1 See Family Law Act 1975 (Cth) s 60I; Family Law Rules 2004 (Cth) Sch 1, Pt 2.

2 See, for example, Linda Fisher and Mieke Brandon, Mediating with Families (Lawbook Co, 3rd ed, 2012); Michael King, Arie Freiberg and Becky Batagol, Non-Adversarial Justice (Federation Press, 2nd ed, 2014) 104-106; Laurence Boulle and Rachael Field, Australian Dispute Resolution: Law and Practice (Butterworths LexisNexis, 2017) Chs 2 and 7. 
and supported negotiation environment, empowering the parties and building their capacity to negotiate mutually appropriate outcomes. However, the process also presents the parties with some significant challenges. The efficacy and legitimacy of the family mediation process demands that these challenges be properly understood and recognised. ${ }^{3}$

One of the core tenets of family mediation is that the parties are the protagonists in the process - negotiating on their own behalf; articulating their own stories, interests, issues and concerns; and giving voice to the needs and interests of their children. ${ }^{4}$ The mediator is expected to use a range of process and communication skills to enable the parties to engage in cooperative and collaborative bargaining. The parties too have responsibilities or they are expected to respect the process and engage in it constructively. In order to achieve mutual and sustainable outcomes, the parties are asked to make a genuine effort and demonstrate, at least to some extent, a level of rational, reasonable negotiation. ${ }^{5}$ This can be challenging, because the post-separation period is often one of the most chaotic, uncertain, stressful and emotional times of the parties' lives. ${ }^{6}$ The process therefore asks a lot of the parties, even when supported by the mediator's presence and expertise.

The factors articulated above make it important to clearly understand the nature of the challenges facing the parties in family mediation. Mediation theory has often glossed over these challenges, positing that the process itself effectively addresses or counteracts them. ${ }^{7}$ For example, it is assumed that the informal nature of family mediation makes it a less challenging negotiation environment because there are no formal

3 Compare Rachael Field and Jonathan Crowe, 'The Construction of Rationality in Australian Family Dispute Resolution: A Feminist Analysis' (2007) 27 Australian Feminist Law Journal 97; Jonathan Crowe and Rachael Field, 'The Problem of Legitimacy in Mediation' (2008) 9(1) Contemporary Issues in Law 48; Susan Armstrong, 'Recognition and Relationality with Families and Children from Minority Cultural and Faith Backgrounds in Australian Family Dispute Resolution' (2015) 29 Australian Journal of Family Law 203.

4 Jay Folberg and Alison Taylor, Mediation: A Comprehensive Guide to Resolving Conflict Without Litigation (Jossey-Bass, 1984); Jay Folberg, Ann Milne and Peter Salem (eds), Divorce and Family Mediation: Models, Techniques, and Applications (Guilford Press, 2004).

5 See, for example, Hilary Astor, 'Making a Genuine Effort in Family Dispute Resolution: What Does It Mean?' (2008) 22 Australian Journal of Family Law 102. See also Field and Crowe, above n 3.

6 See, for example, Peter Reder and Clare Lucey, Assessment of Parenting: Psychiatric and Psychological Contributions (Routledge, 2014); Hamilton I McCubbin and Charles R Figley, Stress and the Family: Coping with Normative Transitions (Routledge, 1983); Rudolf Moos (ed), Coping with Life Crises: An Integrated Approach (Springer, 1986).

$7 \quad$ See, for example, Joan Kelly, 'Power Imbalance in Divorce and Interpersonal Mediation: Assessment and Intervention' (1995) 13 Mediation Quarterly 85; Joan Kelly and Mary Duryee, 'Women and Men's Views of Mediation in Voluntary and Mandatory Mediation Settings' (1992) 30 Family and Conciliation Courts Review 34; Joan Kelly, 'Mediated and Adversarial Divorce: Respondents' Perceptions of Their Processes and Outcomes' (1989) 24 Mediation Quarterly 71. 
legal rules of procedure and evidence that have to be followed. It is also assumed that the even-handed facilitated structure of the process and the emphasis on relational party self-determination and collaborative negotiation evens out the negotiation playing field. For these reasons, it is common (particularly in the form of family mediation practised in Family Relationships Centres) for the parties in family mediation not to be legally represented. ${ }^{8}$

This article argues that the challenges parties face in family mediation must be better recognised and accommodated if the process is truly to support them to reach effective and mutual outcomes. We argue that, although family mediation has many built-in support elements, it is nonetheless structured by underlying expectations and aspirations that may be opaque to the parties, particularly as they are often first-time, inexperienced participants. These expectations potentially create hidden barriers for parties who lack knowledge of the family mediation process and the surrounding legal framework. We argue that mediators have an ethical obligation to be aware of these barriers and work actively to address them.

The article begins by outlining a theoretical framework for understanding the background norms of the family mediation environment. We use Ludwig Wittgenstein's notion of a language game to explain the underlying conventions of different forms of social discourse. ${ }^{9} \mathrm{We}$ argue that parties without previous exposure to family mediation often experience what might be termed a clash of genres, whereby the modes of communication and conduct with which they are familiar in fact conflict with the implicit expectations of the mediation process. ${ }^{10} \mathrm{~A}$ clash of genres potentially compromises the parties' capacity to negotiate effectively in family mediation. Furthermore, the nature of a clash of genres is such that it often cannot be easily articulated and may go unacknowledged.

The article then looks more closely at the features of the family mediation environment. We turn first to the emphasis in mediation on party self-determination, arguing that while this focus has many positive features, it tends to exacerbate, rather than diminish, the possibility of a clash of genres. We explore how the informal nature of the mediation process renders it porous; its structure is prone to be shaped by the norms of the language game of mediation. We also consider the interaction between

8 See, for example, Australian Government Attorney General's Department, Operational Framework for Family Relationship Centres (2007). Compare Lawrie Moloney et al, Evaluation of the Family Relationship Centre Legal Assistance Partnerships Program: Final Report (Australian Institute of Family Studies, 2011). For further discussion of the role of lawyers in family mediation, see John Dewar, 'Family Law and its Discontents' (2000) 14 International Journal of Law, Policy and the Family 59; Becky Batagol, 'Fomenters of Strife, Gladiatorial Champions or Something Else Entirely? Lawyers and Family Dispute Resolution' (2008) 8 Queensland University of Technology Law and Justice Journal 24.

$9 \quad$ Ludwig Wittgenstein, Philosophical Investigations (Macmillan, 2nd ed, 1968).

10 We first suggested this way of thinking about family mediation in Field and Crowe, above n 3 . 
mediation and the more formal principles and procedures of family law, noting that mediation tends to mirror to some extent the expectations of the formal legal framework. We conclude that parties who lack an understanding of these features of the family mediation environment may face significant difficulties in effectively advancing their interests.

The article concludes by exploring the implications for mediator ethics of the problem outlined in the preceding sections. We look at the ethical role of the mediator in the family dispute resolution process, arguing that a rethinking of mediator ethics is required if mediators are to effectively support the parties to participate to their full potential. In our view, mediators must play an ethically active role in preparing and supporting the parties to operate effectively within the mediation language game. This requires a more sophisticated understanding of party self-determination that goes beyond simply letting the parties drive the process.

\section{Language Games and Clashes of Genres}

It is useful to begin our analysis of family mediation by looking at the implicit expectations that lie behind different forms of social interaction. Diverse social environments reflect different expectations as to appropriate or expected forms of speech and behaviour. The expectations governing behaviour in a courtroom, for example, are different from those operating at a party, in a lecture theatre or on a sporting field. This is not only because those forms of activity involve different objectives, but because different approaches are needed to communicate effectively in each different environment. In other words, there are diverse conventions operating in each setting that are predictive of the potential of the success or failure of communicative aims.

In a courtroom, for example, arguments couched in terms of legal principles, rules of evidence and so forth will be effective, whereas statements that fall outside those rules may fail to be heard. At a party, certain types of comments will contribute to smooth conversation, while other types (such as offensive jokes, inappropriate questions or sharing of overly personal information) may cause social discomfort and be ignored or shunned by other party-goers. In a university lecture theatre, some student contributions will be welcomed and recognised by the lecturer (such as constructive questions and comments), while others (such as unsolicited, disruptive interjections, personal conversation or irrelevant comments) are likely to be dismissed, ignored or challenged. Similar conventions of appropriate speech and behaviour apply in many other types of social contexts.

\section{A The Role of Language Games}

A deeper understanding of the different forms of discourse that arise in social life can be achieved by drawing on Wittgenstein's concept of a language game. Wittgenstein describes a language game as a set of rules for the use of language in social interaction, with 'the speaking of language 
[being] part of an activity, or of a form of life'. ${ }^{11}$ Wittgenstein notes that language fundamentally influences - and, indeed, constructs - the ways in which people interact. Language is linked to social behaviour and to the social dynamic. ${ }^{12}$ People associate certain words and phrases with particular forms of behaviour and vice versa.

The notion of a language game therefore refers to a holistic form of social behaviour, where language and behaviour intertwine to create a web of expectations that are specific to that context. Certain forms of language go together with certain types of actions. It is difficult, if not impossible, for an outsider to a specific context, someone who lacks preexisting knowledge of the linguistic and behavioural conventions of that context, to appreciate all the linkages that are taken for granted by those who are more familiar with this backdrop. Wittgenstein makes the point that people are often unable to participate seamlessly in a language game unless they already understand, to a certain extent, the rules that apply.

Wittgenstein illustrates this point through the example of the name of a piece in chess. ${ }^{13}$ If you are shown a piece from a chess set and told, 'this is the king', it does not show you how to use the piece, unless you already understand the rules of the game. On the other hand, if you do know the rules of the game and you are told that a certain piece is the 'king', then you will know how to use it. The name 'king', when affixed to a specific piece, will tell a competent chess player to only move it one square in any direction, to protect it from threats by opposing pieces and so forth. This complex web of associations, however, will be inaccessible to the person who is unfamiliar with the background rules.

A person who lacks an understanding of the rules of chess will be unable to play the game, even if they are given fragments of relevant information, such as the names of the pieces. Similarly, in the courtroom, there are well-documented difficulties that arise when an unrepresented litigant attempts to engage in courtroom advocacy. ${ }^{14}$ The litigant may be told at the outset, 'that is the judge', 'this is the rule against hearsay' and so on. However, they still lack the complex web of knowledge and expertise that would enable them to successfully navigate the required

11 Wittgenstein, above n 9, 11 [23].

12 Ibid 4 [6].

13 Ibid 15 [31].

14 For discussion of this issue in the Australian family law context, see Catherine Caruana, 'Meeting the Needs of Self-Represented Litigants in Family Law Matters' (2002) 62 Family Matters 38; Rosemary Hunter et al, The Changing Face of Litigation: Unrepresented Litigants in the Family Court of Australia (Law and Justice Foundation of New South Wales, 2002); John Dewar, Jeff Giddings and Stephen Parker, 'The Impact of Legal Aid Changes on Family Law Practice' (1999) 13 Australian Journal of Family Law 33; Ian Coleman, 'Unrepresented Litigants and the Family Court' (1998) 73 Reform 41; Rosemary Hunter, 'Litigants in Person in Contested Cases in the Family Court' (1998) 12 Australian Journal of Family Law 171. See also generally Jess Smith and Victoria Worrell, 'Assessing the Impact of Self-Represented Litigants' (2015) 37(9) Bulletin (Law Society of South Australia) 15; Boulle and Field, above n 2, Ch 6. 
speech and behaviour of the courtroom context. For that reason, it is generally unrealistic to expect unrepresented litigants without any form of legal training to engage in the process effectively without some form of assistance. ${ }^{15}$

Chess games and courtroom interactions are relatively formal modes of behaviour. However, part of Wittgenstein's point is that even less formal types of social interaction are structured by underlying expectations. As we saw above, it is possible for inexperienced participants to unwittingly flout the applicable conventions at a party or in a lecture theatre, no less than in the courtroom. The consequences may be less serious, but in each case effective communication and behaviour depends on understanding and internalising the background norms that make up the language game applicable in that context.

In terms of formality, family mediation falls somewhere between the highly structured, formalised environment of the courtroom and the more informal context of a social conversation. However, the stakes are higher than in many other contexts, since the futures of families hang in the balance. As Jean-François Lyotard notes in reference to Wittgenstein's theory, the term 'language game', with its frivolous connotations, can seem inapt when one considers what may be at stake. 'You don't play around with language. And in this sense, there are no language games. There are stakes tied to genres of discourse. ${ }^{16}$

It is therefore important to take seriously the barriers that exist to effective participation in family mediation for parties who are unfamiliar with the process and lack pre-existing knowledge of its conventions. Parties in family mediation, particularly those who already experience a power differential, need to be able to engage with the language game of family mediation in order to articulate their interests and those of their children. However, this requires a level of background knowledge that it is easy to take for granted. Recognising the language game at work in family mediation therefore takes on political significance, with issues of fairness and justice potentially at stake. ${ }^{17}$

\section{B Recognising Clashes of Genres}

Many of the problems people face in negotiating unfamiliar modes of social discourse arise from what we might term clashes of genres. A clash of genres occurs when a person accustomed to operating within one language game seeks to follow the same modes of communication and behaviour

15 See, for example, William Fotherby, 'Law that is Pro Se (Not Poetry): Towards a System of Civil Justice that Works for Litigants without Lawyers' (2010) 16 Auckland University Law Review 54; Margaret Castles, 'Self-Represented Litigants: A Major 21st Century Challenge' (2015) 37(9) Bulletin (Law Society of South Australia) 14.

16 Jean-François Lyotard, The Différend: Phrases in Dispute (Georges Van Den Abbeele trans, University of Minnesota Press, 1988) 137 [188]. Ibid 139 [192]. 
within a context governed by a different language game. ${ }^{18}$ For example, a person accustomed to swearing when among friends may use the same language at a social gathering where it offends or alienates the listeners. Similarly, a person accustomed to using highly emotive language when engaged in personal negotiations may take the same approach when arguing in a courtroom, where it is likely to prove counterproductive.

The highly structured environment of the courtroom means that even a person unfamiliar with it is likely to be aware that it calls for different behaviour than in other types of social contexts. Mediation, as we have seen, is less formal than the courtroom; however, this relative informality is a double-edged sword for the inexperienced player. On the one hand, formal rules and procedures do not need to be followed in order to be heard. On the other hand, the sense of informality may give parties the misleading impression that mediation lacks its own conventions of effective speech and behaviour.

For example, a clash of genres may arise in family mediation if a party communicates using the framework of adversarial negotiation, employing aggressive and positional language, rather than recognising and responding to the expected focus on collaborative, cooperative and interest-based communication. This kind of behaviour is by no means uncommon in mediation, but the party employing it may not understand why it is out of place and, therefore, the risks involved in employing it. An inexperienced participant in mediation might also rely on other inappropriate genres of discourse, such as the genres governing personal conversation or negotiation within the privacy of a relationship.

The role of the mediator, of course, is to ensure that both parties are heard and their emotions are heard but managed. Family mediators may attempt to discourage aggressive positioning, in order to facilitate positive option generation and collaborative bargaining. Our point, though, is that this is a more complex exercise than it might at first appear. The expectations of the family mediation process will not be met by overly legalistic argument, but nor will they be satisfied by overly emotive contributions. It may seem obvious to the mediator what forms of behaviour and speech are appropriate, but this may be far from evident to the parties. Furthermore, the parties may have different levels of understanding that prevent them from engaging equally in the process.

We do not mean to suggest that emotive approaches can never succeed in family mediation. An emotional or undiplomatic participant may sometimes gain an advantage in negotiations by setting the agenda or wearing down the other party. They may cry or disengage from the process and leave the other party in a difficult position. However, the approach is

18 The notion of a clash of genres, as we use it here, draws significantly on Lyotard's notion of the differend. See Lyotard, above n 16. For further discussion, see Field and Crowe, above n 3; Jonathan Crowe, 'Reinterpreting Government Neutrality' (2004) 29 Australian Journal of Legal Philosophy 118; Constance Youngwon Lee and Jonathan Crowe, "The Deafening Silence of the "Comfort Women": A Response Based on Lyotard and Irigaray' (2015) 2 Asian Journal of Law and Society 339 . 
risky. The other party may exploit it by sticking more closely to expected modes of conduct and depicting the first party as unbalanced, irrational or unconcerned about the children's best interests. It is also possible that an emotive approach could lead to the mediation being abandoned, leaving the parties exposed to the risks of litigation. An overly emotive or disengaged approach could also lead the mediator to conclude that the party did not make a genuine effort, which in theory creates the potential for an adverse costs order. ${ }^{19}$

The implicit and unarticulated nature of language games means that clashes of genres are insidious and prone to go unnoticed. This is problematic given the political significance of family mediation. In the case of a clash of genres in family mediation, the fairness of negotiations may be compromised, without this being obvious or straightforwardly discernible in the outcome. The parties will typically be unable to explicitly identify or articulate the nature or existence of the clash of genres. By comparison, an injustice that occurs in a more formalised setting such as a courtroom may be more easily noticed and remedied, particularly when all parties are aware of the applicable norms of discourse. ${ }^{20}$

The fact that courtroom litigation is dominated by legal professionals means that the applicable genre can become highly specialised, without compromising effective communication. ${ }^{21}$ Indeed, context-appropriate specific communication can be achieved through a common language used by all the parties. It is for this reason, however, that unrepresented litigants face such significant challenges. They are required to negotiate a highly complex language game, premised on a background store of knowledge that they simply do not possess. As we saw previously, the unrepresented litigant is like the person in Wittgenstein's story, who is told that a chess piece represents the 'king', without knowing the rules of the game. Experienced advocates, by contrast, are the grandmasters of the language game of law. Their background knowledge enables them to operate successfully and with confidence within the courtroom.

The average participant in family mediation comes to the process as a novice, not a grandmaster. There is no guarantee that a particular party will have any prior familiarity with the speech and behaviour norms of family mediation; they will not know the rules of the family mediation language game. It follows that family mediation is not an environment where it can be assumed that everyone is following the same conventions, or that the process evens or levels the negotiation field. The potential for a clash of genres in family mediation is therefore high. Consequently, parties who can express their interests while complying with the genre are likely to gain an advantage over those who lack the same level of knowledge. This creates the potential for inequities to arise within the process.

19 Family Law Act 1975 (Cth) s 60I(8).

20 Compare Lyotard, above n 16, 196-197.

21 For further discussion of the legal genre of discourse, see Jonathan Crowe, 'Natural Law in Jurisprudence and Politics' (2007) 27(4) Oxford Journal of Legal Studies 775, 785-786; Crowe, 'Reinterpreting Government Neutrality', above n 18. 


\section{The Mediation Language Game}

We suggested in the previous section that participants in family mediation may be disadvantaged if they fail to grasp the conventions of the mediation language game. These conventions are complex, but are rarely fully articulated and may be taken for granted. The converse is also true; parties who understand the rules of the game will be able to make the most of the negotiation opportunities offered. In this section, we look in more detail at two particular features of the family mediation process that shape the applicable genre of discourse. These are, first, the notion of party self-determination; and, second, the fact that the process may be implicitly guided by formal legal rules and principles.

\section{A The Porosity of Mediation}

One generally positive feature of family mediation is its emphasis on party self-determination. ${ }^{22}$ Party self-determination is a process goal of mediation driven by the value of party autonomy. ${ }^{23}$ The notion encompasses a number of related ideas, including direct participation, control over the content of a dispute, and party dignity, self-agency and empowerment. ${ }^{24}$ As Nancy Welsh notes, party self-determination is widely described as 'the fundamental principle of mediation'. ${ }^{25}$ Welsh usefully summarises party self-determination in terms of four core characteristics: active and direct participation by the parties in communicating and negotiating; party choice and control over the substantive norms that guide their decision-making; party involvement in the creation of settlement options; and party control over the terms and adoption of any agreement. ${ }^{26}$

A central aspect of the mediator's ethical role is to support party selfdetermination. ${ }^{27}$ This feature of mediator ethics emphasises 'the ability

22 The National Mediator Accreditation System (NMAS) now defines 'mediation' as 'a process that promotes the self-determination of participants'. See Mediation Standards Board, National Mediator Accreditation System: Practice Standards (2015) ss 2, 9.

23 For further discussion of the values and goals of dispute resolution processes see Boulle and Field, above n 2, Ch 4. See also Gerald Dworkin, The Theory and Practice of Autonomy (Cambridge University Press, 1988) 122; Robert A Baruch Bush and Joseph P Folger, The Promise of Mediation: The Transformative Approach to Conflict (Jossey-Bass, 2005).

24 Jacqueline M Nolan-Haley, 'Self-Determination in International Mediation: Some Preliminary Reflections' (2005) 7 Cardozo Journal of Conflict Resolution 277.

25 Nancy A Welsh, 'The Thinning Vision of Self-Determination in Court-connected Mediation: The Inevitable Price of Institutionalization?' (2001) 6 Harvard Negotiation Law Review 1, 3.

26 Ibid 4.

27 See, for example, Rachael Field, 'Mediation Ethics in Australia - A Case for Rethinking the Foundational Paradigm' (2012) 19 James Cook University Law Review 41; Rachael Field, 'Rethinking Mediation Ethics: A Contextual Method to Support Party Self-Determination' (2011) 22(1) Australasian Dispute Resolution Journal 8; Rachael Field, 'Exploring the Potential of Contextual Ethics in 
of individuals to speak for themselves' and an 'individual's competency and right to make their own decisions'. ${ }^{28}$ Mediators do not impose an outcome on the parties; ${ }^{29}$ rather, they reinforce the relational orientation of the process, ensuring that it creates the potential for outcomes that are 'just to all parties concerned'. ${ }^{30}$ In this way, parties are situated as having the standing to seek a resolution of the dispute that recognises their individual needs and interests. The mediation process achieves this by remaining relatively informal and unstructured. However, the lack of formal structure renders mediation porous; it is prone to be infiltrated and shaped by the unstated expectations of both the mediator and the parties.

Family mediation commonly commences with the mediator setting out ground rules, such as that the parties will 'respect the process' ${ }^{31}$ However, the exact content of such a ground rule is, of course, intrinsically vague. It is at this level that the porosity of mediation begins to become apparent. Inherent in the establishment of ground rules are a number of expectations, hopes or aspirations for how the process will work. The mediator generally expects - or at least aspires - that the parties will respect the process by listening actively and responsively to each other and engaging in cooperative and collaborative communication. Mediators generally also expect or hope that the parties will attempt to engage in consensus bargaining and positive option generation. ${ }^{32}$ This normative context is well known to the mediator, but may be somewhat opaque for the parties.

Mediators will, of course, often attempt to make these expectations and aspirations clear during party preparation or the mediator's opening statement. However, it is difficult - if not impossible - to convey the full extent of the expectations and hopes for the process in such a format. The informal and party-directed nature of mediation, on the other hand, risks giving the impression that there are few or no rules or conventions that the parties need to know to succeed in the process. In other words, mediation's emphasis on self-determination may give parties the misleading idea that there is no applicable language game to be learnt. The parties are likely to be at an informational deficit in relation to the mediator's knowledge and objectives, lacking a real grasp of the expectations at play.

Mediation' in Francesca Bartlett, Reid Mortensen and Kieran Tranter (eds), Alternative Perspectives on Legal Ethics (Routledge, 2010).

28 Marsha Lichtenstein, 'Mediation and Feminism: Common Values and Challenges' (2000) 18 Mediation Quarterly 19, 21.

29 Jacqueline M Nolan-Haley, 'Informed Consent in Mediation: A Guiding Principle for Truly Educated Decision-Making' (1999) 74(3) Notre Dame Law Review 775, 790.

30 Marian Roberts, 'Systems or Selves? Some Ethical Issues in Family Mediation' (1992) 10 Mediation Quarterly 3, 11.

31 Ruth Charlton and Micheline Dewdney, The Mediator's Handbook: Skills and Strategies for Practitioners (Lawbook Co, 2nd ed, 2004) 12-14, 18; Laurence Boulle, Mediation: Principles, Process, Practice (LexisNexis, 2nd ed, 2005) 184.

32 Compare Hilary Astor, 'Making a Genuine Effort in Family Dispute Resolution: What Does It Mean?' (2008) 22 Australian Journal of Family Law 102, 113. 
For this reason, somewhat paradoxically, the mediator's commitment to party self-determination may make it more difficult in practice for participants to effectively learn and internalise the rules of the applicable language game. The more parties are left to speak for themselves and make their own decisions, the less they can draw on the expertise and guidance of others to negotiate the conventions of the mediation process. The mediator's commitment to self-determination may therefore make it difficult for the parties to learn the language game of mediation, which in turn may make it difficult for them to achieve self-determination in any true sense of the term. The answer, as we suggest below, is not to abandon self-determination as a guiding principle of mediator ethics, but rather to reconceptualise the notion to take account of the dynamics described above.

\section{B Mediation and the Legal Paradigm}

Another distinctive feature of family mediation is that it operates within the context of the formal principles and procedures of family law, without being strictly constrained by them. Family mediation occurs within the framework of the Family Law Act 1975 (Cth) and for this reason it can tend to mirror, at least to some extent, the expectations of the formal legal environment, both in terms of content and process. There are, of course, important differences between the mediation and courtroom environments. The courtroom genre of discourse, as we noted above, is focused on positional argumentation where there is a third party arbiter - namely, the judge - to make a binding decision. Mediation, on the other hand, is a collaborative bargaining process focused on providing the parties with an opportunity to exercise self-determination in presenting and resolving their dispute. ${ }^{33}$

The interests-based focus of mediation (as opposed to the rights-based focus of the courtroom) may give parties the impression that the process and its outcomes are not influenced by formal legal rules. ${ }^{34}$ This impression may be bolstered by the relatively informal and party-driven nature of the process. The reality, however, is that family mediation - like mediation generally - inevitably takes place 'in the shadow of the law' ${ }^{35}$ Despite mediation's relatively unstructured nature, the law still provides the general principles and concepts that serve as the implicit backdrop and

$33 \quad$ See Baruch Bush and Folger, above n 23.

34 Compare Boulle, above n 31, 28-29; Welsh, above n 25, 3-4.

35 Robert Mnookin and Lewis Kornhauser, 'Bargaining in the Shadow of the Law: The Case of Divorce' (1979) 88 Yale Law Journal 950. We acknowledge, however, the work of Becky Batagol and Thea Brown, which cautions that this effect should not be overstated. See Becky Batagol and Thea Brown, Bargaining in the Shadow of the Law: The Case of Family Mediation (Federation Press, 2011). For further discussion, see Boulle and Field, above n 2, Ch 11; Field and Crowe, above n 3, 104-107. 
framework for negotiations. ${ }^{36}$ This legal framework is further expressly enshrined in the relevant parts of the Family Law Rules. ${ }^{37}$

At a broader level, there is a sense in which all forms of social discourse take place in the shadow of law. Norms and concepts that enjoy legal force tend to be mirrored or adopted in other social contexts. This is because legal norms enjoy a privileged normative status in the social environment. As Joseph Raz notes, legal systems are distinguished in part by their comprehensiveness - 'they claim authority to regulate any type of behaviour' - and they claim supremacy over other normative systems operating within the community. ${ }^{38}$ A normative system that makes these types of overarching claims to authority will naturally find its content mirrored to some degree in other types of social institutions.

It follows that the normative claims of family law will tend to influence the norms of family mediation practice. The existence of legal rules about family matters implies that family disputes ought to be resolved along those lines, thereby imposing a set of social expectations and aspirations that cannot help but play some role in the mediation process. The Family Law Act, for example, imposes a strong expectation that parents will be child-focused in negotiating parenting arrangements; specifically, there is an expectation that negotiations will keep the child's best interests clearly and consistently in mind. ${ }^{39}$ It follows that parties who possess a general understanding of the law relating to parental responsibility and the best interests of the child may be better equipped to engage effectively in the mediation negotiation environment than those who lack such knowledge.

Family mediators operating within the Family Law Act are further obliged to direct the parties' attention to a range of other factors when negotiating parenting arrangements, including the desirability of the child spending 'substantial and significant time' with each parent and issues about the 'reasonable practicability' of proposed outcomes. ${ }^{40}$ The mediator is likely to enter the process with some understanding, guided by the law, of what these concepts mean. This, in turn, will play a role in determining the mediator's expectations and aspirations for the process. A party who has some grasp of this framework will be well placed to interact

36 Olivia Rundle, 'Barking Dogs: Lawyer Attitudes Towards Direct Disputant Participation in Court-Connected Mediation of General Civil Cases' (2008) 8 Queensland University of Technology Law and Justice Journal 77, 87.

$37 \quad$ Family Law Rules 2004 (Cth) Sch 1, Pt 2, s 1(6)(a).

38 Joseph Raz, Practical Reason and Norms (Oxford University Press, 1999) 150-152. For further discussion, see Crowe, 'Reinterpreting Government Neutrality', above n 18.

39 Family Law Act 1975 (Cth) s 63DA(2)(a)(ii). See also Jennifer McIntosh, Yvonne Wells and Caroline Long, 'Child-Focused and Child-Inclusive Family Dispute Resolution: One Year Findings from a Prospective Study of Outcomes' (2007) 13 Journal of Family Studies 8. For a discussion and critique of the best interests of the child principle in Australian family law, see Jonathan Crowe and Lisa Toohey, 'From Good Intentions to Ethical Outcomes: The Paramountcy of Children's Interests in the Family Law Act' (2009) 33 Melbourne University Law Review 391.

40 Family Law Act 1975 (Cth) s 63DA(2)(a), (b). See also ss 63DA(3), 65DAA(5). 
seamlessly with the mediator's expectations and effectively articulate their interests - in effect they will be able to play the family mediation language game. A party who lacks this knowledge, by contrast, may be placed at a disadvantage in playing the relevant language game.

\section{Rethinking Mediator Ethics}

We argued in the previous sections that the family mediation process incorporates implicit conventions of appropriate speech and conduct that may be opaque to inexperienced participants. Parties who fail to appreciate and internalise these conventions may not be able to make the most of the negotiation opportunities offered by the mediation process. This signals an issue of fairness that warrants further attention. The question therefore arises as to what can be done to assist parties to engage effectively with the mediation environment. The current section considers the implications of this challenge for mediator ethics. We consider how mediators can help parties play the language game of mediation and what this means for mediator impartiality and party self-determination.

\section{A Recognising Mediation Practice}

We argued in the previous section that family dispute resolution practitioners bring pre-existing expectations to the mediation process that play an important role in structuring the negotiations. These expectations may involve the nature of the mediation process itself or the normative framework provided by the rules and principles of family law. We also suggested that parties are, to a large extent, on their own in dealing with the requirements of family mediation, especially if lawyers are excluded from the process. However, it might be thought that this view of the mediation environment understates the constructive role mediators can and do play in preparing and informing the parties.

Many family mediation practitioners are highly reflective about their role and the dynamics of the mediation context. Mediators may well be aware of the expectations they bring to the process and strive through selfreflection to avoid imposing these inappropriately on the parties. There is also undoubtedly an important role for the mediator in assisting parties to cope with the demands and expectations of the process. Mediators often spend significant time and effort explaining to the parties what mediation involves. ${ }^{41}$ This occurs in intake processes, at the start of the mediation and during negotiations.

Family mediators have the capacity to respond actively and constructively to the dynamics of unfolding negotiations, including providing information, guidance and encouragement to parties who struggle to make their voices heard. They can reflect upon and respond to their own biases regarding language proficient and highly educated parties or parties who seem under-equipped, emotional or overwhelmed. They can also be alert 
to power imbalances arising from both relational factors and an imbalance in levels of preparation and knowledge, seeking to address these while remaining within the confines of their role.

Mediators routinely provide legal information to the parties in family mediation. That is, they explain the legal context within which the process occurs and the need to focus on the best interests of children. ${ }^{42}$ They cannot ensure that parties internalise these principles or use them effectively and consistently to frame their contributions, but they can at least take steps to reduce informational deficits. Mediators also frequently help the parties to learn and apply the basic skills of negotiation, both in plenary sessions and in private caucus; indeed, supporting the parties in the practice of basic negotiation skills is a recognised part of the mediator's role. ${ }^{43}$ Finally, mediators will often be aware that many parties lack any experience with the mediation process at all and will modify their approaches accordingly.

Mediators therefore certainly have something to offer in terms of the issues outlined in this article. Indeed, one of our chief aims in exploring this area is to provide a focal point for reflective approaches to mediation practice and recognition of the complex and nuanced nature of the mediator's role. It is also necessary, however, to be aware of the limits on how far mediators can effectively address the problem we have outlined, particularly within the current ethical paradigm for mediation. This is because the prevailing ethical paradigm imposes its own expectations on mediators concerning the nature and aims of the process which constrain their ability to address power imbalances and help inform the parties.

\section{B Impartiality and Self-Determination}

One of the chief expectations placed on mediators in the mediation process is that of mediator impartiality. ${ }^{44}$ Mediator neutrality and impartiality have long been at the heart of mediation theory and practice; for many, these notions are the "hallmark of mediation and one of the primary reasons for its success as an alternative dispute resolution method'. ${ }^{45}$ The precise meaning of these terms has been the subject of long-running discussion and debate. They have become, in many ways, elusive and idealised

$42 \quad$ Family dispute resolution practitioners are, indeed, required to provide this kind of general advice under the Family Law Act (Cth) s 63DA.

43 Boulle, above n 31, 219.

44 See, for example, Hilary Astor, 'Mediator Neutrality: Making Sense of Theory and Practice' (2007) 16 Social and Legal Studies 221; Hilary Astor, 'Rethinking Neutrality: A Theory to Inform Practice - Part I' (2000) 11 Australasian Dispute Resolution Journal 73; Hilary Astor, 'Rethinking Neutrality: A Theory to Inform Practice - Part II' (2000) 11 Australasian Dispute Resolution Journal 145; Field and Crowe, above n 3, 110-114.

45 William A Donohue, 'Communicative Competence in Mediators' in Kenneth Kressel and Dean C Pruitt (eds), Mediation Research: The Process and Effectiveness of Third-Party Intervention (Jossey-Bass, 1989) 322-343. See also Hilary Astor, 'Mediator Neutrality', above n 43; Folberg and Taylor, above n 4, 7-8; Christopher Moore, The Mediation Process: Practical Strategies for Resolving Conflict (Jossey-Bass, 1996) 14. Compare Boulle, above n 31, 31. 
concepts; ${ }^{46}$ leading commentators have described neutrality in particular as 'folklore' and a 'myth'. ${ }^{47}$ It is nonetheless possible to pick out some key components of mediator impartiality as conventionally understood. At its core is the principle that the mediator is to be even-handed between the parties and uninvolved in the content of the dispute. An impartial mediator is expected to lack bias, have no interest in the outcome and make no judgement about the parties and their respective claims. The picture that emerges is that the impartial mediator is detached and uninvolved, whereas an involved and interventionist mediator oversteps the boundaries of their ethical role.

There is a clear connection here between mediator impartiality and the notion of party self-determination, as discussed previously in this article. Party self-determination, as generally understood, requires the parties and not the mediator to determine the course of the content of negotiations. It emphasises the ability of the parties to speak for themselves and make their own decisions. In this respect, both mediator impartiality and party self-determination are in direct tension with the capacity of practitioners to assist parties to overcome informational deficits and engage effectively with the mediation language game. This is particularly the case where one party is better equipped than the other to engage with the process. In such a case, a mediator who assists and advises the affected party not only risks seeming interventionist, but may also appear biased by providing aid to one party over another.

A related problem concerns the tension between the ideal of a detached, impartial mediator and the reality, considered in the previous section of this article, that mediators bring their own expectations to the family mediation environment. Mediators may attempt to be impartial, but they inevitably have some expectations or aspirations - however general and modest - for how the process will unfold. At the least, they will hope to help the parties express their interests and reach a mutual outcome an expectation that brings with it an implicit understanding of how the parties might contribute to or hinder that end. Family mediators will often have additional expectations or hopes of creating a child-centred focus for negotiations. These expectations play a role in constructing the language game of family mediation. The parties, however, may not be fully aware of this framework. Furthermore, mediators may be reluctant to speak openly to the parties about their own views and preferences, for fear of being seen as overly prescriptive, biased or interventionist in what is said to be a party-driven process.

Mediators are also constrained in their ability to respond where uncertainty about the applicable legal framework becomes apparent during the course of negotiations. This is partly due to the demands of

46 Howard Gadlin and Elizabeth W Pino, 'Neutrality: A Guide for the Organisation Ombudsperson' (1997) 13 Negotiation Journal 17, 17.

47 Janet Rifkin, Jonathan Millen and Sara Cobb, 'Toward a New Discourse for Mediation: A Critique of Neutrality' (1991) 9(2) Mediation Quarterly 151, 152; Boulle, above n 31, 31 . 
impartiality and self-determination, as discussed above. However, it may also be because providing expert legal advice is seen as clearly outside the mediator's role. If a significant uncertainty manifests itself about the interpretation or relevance of a specific legal principle, a mediator may feel the best they can do is urge the parties to seek independent advice. ${ }^{48}$ This, of course, will not necessarily mean the mediator lacks their own view on the issue; to this extent, the mediator's implicit or subconscious expectations may not be fully mirrored or revealed in their formal advice to the participants.

The ethical obligation of family mediators to help parties play the applicable language game is therefore in tension with traditional conceptions of mediator impartiality and party self-determination. The answer to this dilemma, in our view, is to shift the focus of mediator ethics away from impartiality and towards a revised understanding of self-determination that is more responsive to the dynamics of the mediation process. ${ }^{49}$ Selfdetermination is not just a matter of letting the parties speak and decide their own outcomes. Rather, genuine self-determination depends on the ability of both parties to engage effectively in the mediation language game. This will require the mediator to play an active role in preparing, guiding and informing the parties, both at the start of the process and during negotiations. In some cases, the mediator may need to assist one party in particular where there is a clear imbalance in knowledge and understanding.

\section{Conclusion}

We noted at the start of this article that family mediation offers a range of potential benefits to parties in post-separation disputes. These benefits are only fully realised, however, when all parties have the capacity to engage effectively in the mediation language game. The increasing prominence of mediation as a mode of family dispute resolution means it is crucial that barriers to effective participation are recognised and addressed. A wide range of disputes in family law and other areas are now resolved through mediation, but the legitimacy of those outcomes is often simply taken for granted. ${ }^{50}$ We would suggest that the outcomes of family mediation cannot truly be regarded as legitimate unless the process itself is fair and accessible to all parties. This requires scrutiny of not merely the aspirations of mediation, but also the underlying conventions that structure the process.

Parties who know how to play the mediation language game will have a clear advantage over those who do not, potentially exacerbating the dangers of mediation for vulnerable participants. ${ }^{51}$ Mediators therefore have an ethical duty to ensure that all parties are prepared to engage effectively in the process by understanding the relevant genre of discourse.

48 See Batagol, above n 8, 39.

49 Compare Field and Crowe, above n 3.

50 See Field and Crowe, above n 3.

51 See Field and Crowe, above n 3. 
This role may seem at odds with traditional views of impartiality and self-determination; in reality, though, such a role can be argued to be necessary to ensure that genuine self-determination is a real possibility. We have therefore contended that party self-determination should be reconceptualised to acknowledge the need for the mediator to help parties avoid clashes of genres. This will sometimes require them to play an active role in the process.

We noted above that family mediators already often spend significant time and effort informing and equipping the parties. These existing practices are, in some ways, at odds with traditional views of impartiality and self-determination. The point of our argument is therefore not to critique the practices of family mediators, so much as to bring mediator ethics in line with what mediators are already doing. ${ }^{52}$ Sometimes, it may be necessary to change the practice of mediation to bring it into line with ethical principles; at other times, however, ethical principles need to adapt to the realities of mediation practice. We have suggested that mediator ethics needs to recognise the challenge of preparing parties to play the mediation language game. This will help resolve some of the tensions that exist between traditional theories of mediator ethics and the realities of family mediation.

52 This is consistent with the view of mediator ethics advanced in Jonathan Crowe, 'Ethics and the Mediation Community' (2015) 26 Australasian Dispute Resolution Journal 20. 